\title{
Intravascular adhesion and recruitment of neutrophils in response to CXCL1 depends on their TRPC6 channels
}

\author{
Otto Lindemann ${ }^{1} \cdot$ Jan Rossaint ${ }^{2} \cdot$ Karolina Najder $^{1} \cdot$ Sandra Schimmelpfennig $^{1} \cdot$ Verena Hofschröer $^{1} \cdot$ Mike Wälte $^{1,3}$. \\ Benedikt Fels ${ }^{1} \cdot$ Hans Oberleithner ${ }^{1} \cdot$ Alexander Zarbock $^{2} \cdot$ Albrecht Schwab $^{1}$
}

Received: 3 June 2019 / Revised: 21 December 2019 / Accepted: 3 January 2020 / Published online: 16 January 2020

(C) The Author(s) 2020

\begin{abstract}
Here we report a novel role for TRPC6, a member of the transient receptor potential (TRPC) channel family, in the CXCL1-dependent recruitment of murine neutrophil granulocytes. Representing a central element of the innate immune system, neutrophils are recruited from the blood stream to a site of inflammation. The recruitment process follows a well-defined sequence of events including adhesion to the blood vessel walls, migration, and chemotaxis to reach the inflammatory focus. A common feature of the underlying signaling pathways is the utilization of $\mathrm{Ca}^{2+}$ ions as intracellular second messengers. However, the required $\mathrm{Ca}^{2+}$ influx channels are not yet fully characterized. We used WT and TRPC $^{-1-}$ neutrophils for in vitro and TRPC6 $^{-/-}$chimeric mice (WT mice with WT or TRPC6 ${ }^{-1}$ bone marrow cells) for in vivo studies. After renal ischemia and reperfusion injury, $\mathrm{TRPC}^{-/}$chimeric mice had an attenuated TRPC $^{-1-}$ neutrophil recruitment and a better outcome as judged from the reduced increase in the plasma creatinine concentration. In the cremaster model CXCL1-induced neutrophil adhesion, arrest and transmigration were also decreased in chimeric mice with $\mathrm{TRPC}^{-/-}$neutrophils. Using atomic force microscopy and microfluidics, we could attribute the recruitment defect of $\mathrm{TRPC}^{-/-}$neutrophils to the impact of the channel on adhesion to endothelial cells. Mechanistically, TRPC6 ${ }^{-/-}$neutrophils exhibited lower $\mathrm{Ca}^{2+}$ transients during the initial adhesion leading to diminished Rap1 and $\beta_{2}$ integrin activation and thereby reduced ICAM-1 binding. In summary, our study reveals that TRPC6 channels in neutrophils are crucial signaling modules in their recruitment from the blood stream in response to CXCL1.
\end{abstract}

\section{Key point}

Neutrophil TRPC6 channels are crucial for CXCL1-triggered activation of integrins during the initial steps of neutrophil recruitment.

Keywords TRPC6 channel · Neutrophil recruitment · CXCL1 · CXCR2

Otto Lindemann and Jan Rossaint contributed equally to this work.

Albrecht Schwab

aschwab@uni-muenster.de

1 Institute of Physiology II, Westfälische Wilhelms-Universität, Münster, Germany

2 Department of Anaesthesiology, Intensive Care and Pain Medicine, University Hospital Münster, Münster, Germany

3 Institute of Cell Dynamics and Imaging, Westfälische Wilhelms-Universität, Münster, Germany

\section{Introduction}

Neutrophil recruitment occurs in a precisely orchestrated sequence of events (reviewed in Filippi [1]). In its early phase, the binding of endothelial selectins to P-selectin glycoprotein ligand 1 (PSGL1) triggers an intracellular signaling cascade, resulting in inside-out signaling via PI3K (phosphatidylinositide-3-kinase) and PLC (phospholipaseC). This causes the activation of $\beta_{2}$-integrins, such as LFA1 (integrin $\alpha_{L} \beta_{2}$ ), to an extended conformation with intermediate binding affinity for its ligands [2]. The binding of extended LFA1 to intercellular adhesion molecule 1 
(ICAM-1) induces neutrophil slow rolling on endothelial cells. Thereby, neutrophils are brought into close proximity to the surface of endothelial cells so that they can respond to inflammatory chemoattractants, which are trapped in the glycocalyx of inflamed endothelial cells [3]. IL-8 and CXCL1 induce the extension of LFA1 to its high-affinity conformation in human [4] and murine [5] neutrophils which leads to their firm arrest on endothelial cells. Macrophage-1 antigen (Mac1), the second $\beta_{2}$-integrin which is abundantly expressed on neutrophils, facilitates intravascular crawling of neutrophils from the site of adhesion to the site of emigration through the endothelium into the perivascular tissue [6].

It is well established that multiple steps of the neutrophil recruitment cascade are linked to intracellular $\mathrm{Ca}^{2+}$ signaling. Thus, the activation of $\mathrm{G}$ protein coupled CXC-motif chemoattractant receptor 2 (CXCR2) by its ligand CXCL1 involves PLC activation and the generation of inositol 1,4,5trisphosphate $\left(\mathrm{IP}_{3}\right)$ and diacylglycerol (DAG) [7]. $\mathrm{IP}_{3}$ triggers the $\mathrm{Ca}^{2+}$ release from intracellular stores and subsequent store-operated $\mathrm{Ca}^{2+}$ entry via Orail channels [8]. DAG can directly activate members of the transient receptor potential (TRP) channel family, like TRPC6, leading to $\mathrm{Ca}^{2+}$ influx from the extracellular space [9]. Several $\mathrm{Ca}^{2+}$-permeable channels such as Orail channels $[8,10]$ as well as TRPC1 [11], TRPC6 [12, 13], TRPM2 [14], and TRPV4 channels [15] in neutrophils have been shown to be involved in their recruitment (reviewed in $[16,17]$ ). However, the elucidation of the underlying mechanisms by which these $\mathrm{Ca}^{2+}$ influx channels regulate neutrophil recruitment is complicated by the multitude of chemoattractants. While there seems to be a coupling between TRPC6 channels and CXCR2, data concerning the link between TRPM2 channels and fMLPtriggered signaling are discussed controversially [16]. It is further complicated by the fact that $\mathrm{Ca}^{2+}$ signaling in endothelial (or epithelial) cells has to be considered, too. Indeed, the abovementioned channels are also expressed in endothelial cells [18] and several members of the TRP channel family in endothelial (or epithelial) cells have also been shown to regulate neutrophil recruitment [19-21] (reviewed in [16, 22]).

Based on their link to CXCR2 signaling and the fact that CXCR2 is involved in intravascular arrest of neutrophils [23], a role for TRPC6 channels in the intravascular recruitment steps appears likely. Since TRPC6 channels largely mediate the CXCR2-induced rise of the intracellular $\mathrm{Ca}^{2+}$ concentration [12], they could trigger the activation of the $\mathrm{Ca}^{2+}$ - and DAG-activated guanine nucleotide exchange factor CalDAGGEF1 [24]. CalDAG-GEF1 in turn is an important module of the signaling cascade underlying integrin activation $[25,26]$. Mutations in CalDAG-GEF1 cause leukocyte adhesion deficiency syndrome (LAD III) [27]. In this study, we tested whether TRPC6 channels are central elements of the signaling cascade underlying CXCR2-mediated neutrophil recruitment.
We combined intravital microscopy, single-cell force spectroscopy with atomic force microscopy, $\mathrm{Ca}^{2+}$ imaging, and microfluidic flow chamber assays to investigate the role of TRPC6 channels in murine neutrophils for their recruitment in renal ischemia-reperfusion and cremaster models as well as in in vitro assays.

\section{Methods}

\section{Animals}

All animal experiments were approved by the local authorities (Landesamt für Natur, Umwelt und Verbraucherschutz Nordrhein-Westfalen). Mixed chimeric mice were generated by performing bone marrow transplantation as previously described [28]. Bone marrow cells isolated from WT and $\mathrm{TRPC6}^{-/-}$donor mice were injected intravenously into lethally irradiated C57BL/6J WT-recipient mice. The resulting chimeric mice are designated as WT/WT mice (WT mice with WT bone marrow cells) or WT/TRPC ${ }^{-1-}$ mice (WT mice with $\mathrm{TRPC}^{-/-}$bone marrow cells). In vitro experiments were performed with bone marrow-derived neutrophils isolated either from $\mathrm{C} 57 \mathrm{BL} / 6 \mathrm{~J}$ WT mice or their TRPC6 ${ }^{-/}$littermates.

\section{Ischemia-reperfusion injury model}

The ischemia-reperfusion injury (IRI) model has been described previously [29]. Ischemia was induced by bilateral renal pedicle clamping for $32 \mathrm{~min}$. Kidneys were inspected for immediate color change, indicating successful clamping. After clamp removal, kidneys were checked for a change in color within $3 \mathrm{~min}$ to ensure reperfusion. In animals subjected to sham operation, the surgical procedure was identical except that no clamps were applied. Incisions were closed in two layers and animals were allowed to recover. After $24 \mathrm{~h}$, the mice were euthanized, blood samples were taken by heart puncture, the kidneys were flushed by perfusion through the left ventricle, and both kidneys were harvested to determine the number of neutrophils in the kidney. Serum creatinine levels were determined by using a creatinine assay (Diazyme, Poway, USA) according to the manufacturer's protocol. PMN recruitment into the kidneys was analyzed by flow cytometry after $24 \mathrm{~h} \mathrm{[29].}$

\section{Intravital microscopy}

Intravital microscopy was performed as described before [30]. Mice were anesthetized using injection of $125 \mathrm{mg} / \mathrm{kg}$ ketamine hydrochloride and $12.5 \mathrm{mg} / \mathrm{kg}$ xylazine intraperitoneal. For intravital microscopy (IVM), the cremaster muscle of anesthetized mice was exteriorized and inflammation was induced by superfusion with the respective chemoattractant 
(CXCL1 5 nM, fMLP $100 \mu \mathrm{M}$ ) for $1 \mathrm{~h}$. Postcapillary venules with a diameter between 20 and $40 \mu \mathrm{m}$ were investigated. Leukocyte arrest was analyzed by transillumination intravital microscopy, whereas leukocyte extravasation was investigated by near infrared reflected light oblique transillumination (RLOT) microscopy [31]. IVM was performed on an upright microscope (Axioskop; Zeiss, Göttingen, Germany) equipped with a $40 \times 0.75 \mathrm{NA}$ saline immersion objective and a digital camera (Sensicam QE, Corporation, Romulus, USA). Blood flow centerline velocity was measured using a dual photodiode sensor system (CircuSoft Instrumentation, Hockessin, USA) in order to ensure comparable microvascular hemodynamics in between the groups [32]. Blood flow centerline velocity was measured using a dual photodiode sensor and digital online cross-correlation program (CircuSoft Instrumentation, Hockessin, USA). Centerline velocities were converted to mean blood flow velocities by multiplying with an empirical factor of 0.625 [33]. Wall shear rates $\left(\gamma_{\mathrm{W}}\right)$ were estimated as $4.9\left(8 \mathrm{v}_{\mathrm{b}} / \mathrm{d}\right)$, where $\mathrm{v}_{\mathrm{b}}$ is the mean blood flow velocity, $\mathrm{d}$ is the diameter of the vessel, and 4.9 is a median empirical correction factor obtained from velocity profiles measured in microvessels in vivo [34]. Image analysis was performed using ImageJ (version 1.48) and AxioVision (Zeiss, Göttingen, Germany) software. Emigrated cells were analyzed in an area of $100 \mu \mathrm{m}$ blood vessel length $\times 75 \mu \mathrm{m}$ to each side of a vessel (representing $1.5 \times 10^{4} \mu \mathrm{m}^{2}$ tissue area). Leukocyte arrest was determined before and every minute after intravenous injection of $600 \mathrm{ng}$ CXCL1 [23]. Arrest was defined as leukocyte adhesion longer than $30 \mathrm{~s}$ and expressed as cells per surface area.

\section{Measurement of the cytosolic $\mathrm{Ca}^{2+}$ concentration}

The measurement of the cytosolic $\mathrm{Ca}^{2+}$ concentration $\left(\left[\mathrm{Ca}^{2+}\right]_{\mathrm{i}}\right)$ was performed in $\mu$-slide I chambers (ibidi, Martinsried, Germany). To mimic the physiological conditions during capturing of neutrophils, $\mu$-slides were coated with $3.5 \mu \mathrm{g} / \mathrm{ml}$ E-selectin (R\&D Systems, Minneapolis, USA) overnight. Unspecific binding sites were blocked (1\% fat-free milk in PBS) for $1 \mathrm{~h}$. When indicated, this was followed by $2 \mathrm{~h}$ coating with $1.43 \mu \mathrm{g} / \mathrm{ml} \mathrm{CXCL1}$ in blocking solution. Afterwards, the slides were washed with $2 \mathrm{ml}$ of Ringer solution. Neutrophils from overnight cultures were pelleted $\left(4{ }^{\circ} \mathrm{C}, 1000 \mathrm{rpm}, 10 \mathrm{~min}\right.$ ), resuspended in RPMI 1640 containing $25 \mathrm{mM}$ HEPES, and preincubated with $3 \mu \mathrm{M}$ of the $\mathrm{Ca}^{2+}$ dye Fura-2-AM (Calbiochem, Gibbstown, USA) at $4{ }^{\circ} \mathrm{C}$. After $20 \mathrm{~min}$, cells were pelleted $\left(4^{\circ} \mathrm{C}, 1000 \mathrm{rpm}, 10 \mathrm{~min}\right)$ and resuspended in Ringer solution. During the measurement, a laminar flow of $5 \mathrm{dyn} / \mathrm{cm}^{2}$ was maintained in the slide using a tubing pump (Masterflex C/L 10-60 rpm, 12 VDC, ColeParmer, Vernon Hills, USA). Cells were brought into the flow of this system, and $\left[\mathrm{Ca}^{2+}\right]_{\mathrm{i}}$ was measured during the initial rolling phase. Experiments were carried out at room temperature, and images were acquired in 500-ms intervals. At the end of each experiment using slides coated with Eselectin and CXCL1, the measurements were calibrated by applying $1 \mu \mathrm{M}$ ionomycin (MP Biomedicals, Solon, USA) containing Ringer solution with $5 \mathrm{mM}$ EGTA or $5 \mathrm{mM}$ $\mathrm{Ca}^{2+} \cdot\left[\mathrm{Ca}^{2+}\right]_{\mathrm{i}}$ was calculated as described before [35]. The area under the curve was calculated as integral for the first $5 \mathrm{~s}$ after initial contact to the selectin-coated surface (normalized to base levels of $\left[\mathrm{Ca}^{2+}\right]_{i}$ the cells reached after a few minutes). When slides were only coated with E-selectin, a calibration was not possible because the vast majority of neutrophils did not adhere firmly and rapidly rolled out of the visual field. In this case, we only analyzed background-corrected ratio values of the emissions after exciting at $340 \mathrm{~nm}$ and $380 \mathrm{~nm}$. Further experimental details were described earlier [12].

\section{Single-cell force spectroscopy}

Single-cell force spectroscopy experiments were performed by using atomic force microscopy (AFM) (CellHesion $\AA$ 200, JPK, Berlin, Germany) as described before [36]. All experiments were analyzed using JPK Data Processing (software version 4.2.50). Arrow TL-1 tipless cantilevers (NanoAndMore GmbH, Wetzlar, Germany) were incubated prior to experiments for $30 \mathrm{~min}$ in Cell-Tak (Corning, NY, USA) to make the AFM cantilever sticky for neutrophils. bEnd5 endothelial cells were grown in a monolayer in glass bottom dishes using flexiPERM cell culture inserts (Sarstedt, Nümbrecht, Germany). Twenty-four hours prior to the experiment, bEnd5 cells were stimulated with 5 nM TNF $\alpha$ (PeproTech, Hamburg, Germany). The surrounding glass bottom was coated with $10 \%$ FCS in PBS overnight and washed twice with water. Afterwards, cell culture inserts were removed and the whole dish was washed twice with Ringer solution. Neutrophils were seeded besides the endothelial cells, and the front part (apex) of the Cell-Tak-coated cantilever was brought into contact with a single PMN for $5 \mathrm{~s}$ using a maximal loading force of $1 \mathrm{nN}$ in order to attach the PMN firmly to the AFM cantilever. Measurements were performed in Ringer solution (control) or Ringer solution containing $1.43 \mu \mathrm{g} / \mathrm{ml} \mathrm{CXCL1}$ at $37^{\circ} \mathrm{C}$. The process of attaching neutrophils to cantilevers was highly standardized and optically controlled so that the neutrophils were always at the same position of the cantilever and had the same morphology.

Force-distance curves were obtained by probing bEnd5 cells with the neutrophil-carrying cantilever using $1 \mathrm{nN}$ maximal loading force (Fig. 4a). Positioning of neutrophils above and lowering onto endothelial cells was optically controlled so that they were always placed in the middle between cell nucleus and cell-cell junctions of endothelial cells. To mimic the rapid time course of the formation of adhesive bonds between neutrophils and endothelial cells during rolling and adhesion, the contact time was set to $1 \mathrm{~s}$. Further specific AFM 
parameters were as follows: average AFM cantilever spring constant: $0.02-0.025 \mathrm{~N} / \mathrm{m}$; average deflection sensitivity: $90 \mathrm{~nm} / \mathrm{V}$; $z$-length (pull-off distance): $50 \mu \mathrm{m}$; cantilever velocity during approach/retraction: $5 \mu \mathrm{m} / \mathrm{s}$; sampling rate: $205 \mathrm{~Hz}$. In average, 30 force-distance curves were performed per one individual neutrophil on ten individual endothelial cells. Adhesion forces were determined by analyzing the individual maximum pulling forces.

\section{Rap1 Tat-fusion mutants}

The G12V mutation was introduced into the Rho family small GTP binding protein Rap1A (RAP1A00000) via the QuikChange mutagenesis kit (StrataGene, La Jolla, USA). This mutation induces a constitutively active phenotype (CA). The Tat-proteins from HIV-1 have been shown to be easily taken up by different cell types [37]. The Tat-fusion mutants have been generated as described previously [38].

\section{Microflow chamber assays}

The effect of Rap1 Tat-fusion mutants was analyzed in a previously described microflow chamber system [39]. Rectangular glass capillaries $(20 \mu \mathrm{m} \times 200 \mu \mathrm{m})$ were filled either with E-selectin $(2.5 \mu \mathrm{g} / \mathrm{mL}, \mathrm{R} \& \mathrm{D}$ Systems $)$ and ICAM-1 $(2 \mu \mathrm{g} / \mathrm{mL}, \mathrm{R} \& \mathrm{D}$ Systems $)$ alone or in combination with CXCL1 $(0.07 \mu \mathrm{g} / \mathrm{ml})$ for $2 \mathrm{~h}$ and then blocked for $1 \mathrm{~h}$ using casein (Pierce Chemicals, Dallas, TX, USA). One side of the chamber was connected to a PE 50 tubing (Becton Dickinson) and used to control the wall shear stress in the capillary. The other side of the chamber was inserted into a syringe filled with heparinized whole blood. Whole blood samples from WT or TRPC6 ${ }^{-1-}$ mice were incubated with TAT-fusion mutants $\left(1 \mu \mathrm{M}, 37^{\circ} \mathrm{C}, 30 \mathrm{~min}\right)$ and adherent neutrophils were analyzed by microscopy. One representative field of view was recorded for $1 \mathrm{~min}$ using an SW40/0.75 objective and a digital camera (Sensicam QE; Cooke Corporation, Romulus, USA).

Alternatively, we used $\mu$-slides that were coated o/n with $3.5 \mu \mathrm{g} / \mathrm{ml} \mathrm{E}$-selectin and blocked for $1 \mathrm{~h}$ with $1 \%$ fat free milk in PBS. 500,000 neutrophils (WT or TRPC6 ${ }^{-1-}$ ) were suspended in $1 \mathrm{ml}$ HEPES-buffered Ringer's solution supplemented with different concentrations of CXCL1 (0.03$30 \mu \mathrm{g} / \mathrm{ml})$ or fMLP $(10 \mathrm{nmol} / \mathrm{L}-5 \mu \mathrm{mol} / \mathrm{L})$. When indicated, $3 \mu \mathrm{g} / \mathrm{ml} \mathrm{CXCL1} \mathrm{were} \mathrm{supplemented} \mathrm{with} 5 \mu \mathrm{mol} / \mathrm{l}$ larixyl acetate. This suspension was flown at $5 \mathrm{dyn} / \mathrm{cm}^{2}$ through the $\mu$-slides using a tubing pump (Masterflex C/L 10-60 rpm, 12 VDC, Cole-Parmer, Vernon Hills, USA). After 2 min, the adherent cells were fixed with $3.5 \%$ paraformaldehyde for $30 \mathrm{~min}$. Adherent neutrophils were quantified in three visual fields that were placed at the identical distance from the entrance into the microchannel.

\section{Active Rap1 pull-down assay}

Active Rap1 Pull-Down and Detection Kit was purchased from Thermo Scientific (Pierce Biotechnology, Rockford, USA). A GST-fusion protein of the Rap1-binding domain is coupled to a glutathione agarose resin to specifically pull down active Rap1, which is analyzed by Western blot. For the Pull-Down reaction neutrophils from overnight cultures were pelleted $\left(4^{\circ} \mathrm{C}, 1000 \mathrm{rpm}, 10 \mathrm{~min}\right)$, washed once with RPMI 1640 containing $25 \mathrm{mM}$ HEPES and stimulated for $30 \mathrm{~s}$ with $1.43 \mu \mathrm{g} / \mathrm{ml}$ CXCL1. Afterwards, cells were pelleted and lysed following the manufacturer's protocol. For each PullDown reaction, $400 \mu \mathrm{g}$ total protein was used and the direct flow-through after the pull-down containing the remaining total protein was used as additional loading control in Western blots.

\section{ICAM-1 binding assay}

Integrin binding to LFA-1 was analyzed as described before $[29,40]$. Neutrophils from overnight cultures were incubated with CD11b (clone M1/70; $10 \mu \mathrm{g} / \mathrm{ml}$ ) to avoid Mac-1 binding to ICAM-1. In the presence of ICAM-1/Fc $(20 \mu \mathrm{g} / \mathrm{ml})$ and allophycocyanin-conjugated $\operatorname{IgG}$ (Fc specific) cells were stimulated with CXCL1 $(0.1 \mu \mathrm{g} / \mathrm{ml})$ or left unstimulated in control experiments. Control experiments had shown that ICAM-1 binding is abolished when neutrophils are preincubated with blocking LFA-1 antibodies [40]. ICAM-1 binding was analyzed using flow cytometry.

\section{Statistics}

Data are presented as means \pm SEM. All data were tested for normality and evaluated for statistically significant differences $(p<0.05)$ by means of Student's $t$ test or Mann-Whitney $U$ test. Multiple comparison was tested with ANOVA and Tukey post hoc test. Data outliers were detected with Grubbs or Nalimov tests.

\section{Results}

\section{Renal damage after ischemia-reperfusion is attenuated in $\mathrm{TRPC}^{-1}$ mice}

To investigate the pathophysiological relevance of the TRPC6 channels in neutrophils, we induced renal ischemiareperfusion injury (IRI) in WT/WT and WT/TRPC6 ${ }^{-1}$ chimeric mice. After $24 \mathrm{~h}$ of reperfusion, the serum creatinine levels were determined to assess renal function, and the number of neutrophils in the kidneys was analyzed as a measure of renal inflammation. Serum creatinine levels and neutrophils in the kidney were similar in sham operated WT/WT and WT/ 
$\mathrm{TRPC}^{-/-}$chimeric animals. Serum creatinine increased in WT/WT mice after renal ischemia. In WT/TRPC6 ${ }^{-1-}$ mice the increase was $\sim 30 \%$ lower (Fig. 1a). We observed a similar difference between WT/WT and WT/TRPC6 ${ }^{-1}$ mice with respect to the renal neutrophil count. While the number of neutrophils in the kidneys of WT/WT mice strongly increased, the neutrophil count was $\sim 50 \%$ lower in $\mathrm{WT} / \mathrm{TRPC}^{-/}$mice (Fig. 1b). The improved outcome of the renal ischemiareperfusion injury of $\mathrm{WT} / \mathrm{TRPC} 6^{-/}$chimeric mice is consistent with the idea that TRPC6 channels contribute to the recruitment of neutrophils into the kidneys so that the deletion of TRPC6 channels in neutrophils is protective under this condition.
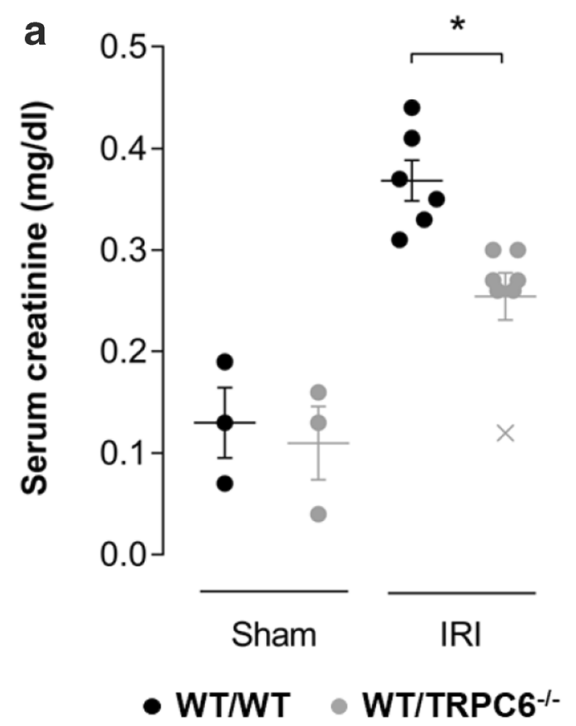

b

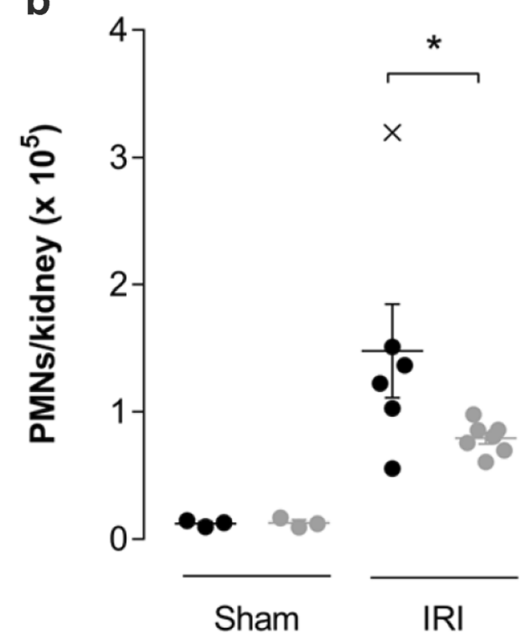

Fig. 1 Neutrophil recruitment and renal damage after ischemia and reperfusion is reduced in WT/TRPC $6^{-1-}$ mice. Serum creatinine (a) and renal neutrophils (b) after ischemia/reperfusion injury (sham: $n=3$, IRI: $n \geq 6$ mice/group). Values are reported as mean values \pm SEM. $* p<0.05$. Data points represented by a cross $(\mathrm{X})$ were identified as outliers and not considered for statistical analysis

\section{Loss of TRPC6 ${ }^{-/-}$channels reduces adhesion and transmigration of neutrophils in vivo}

Neutrophil recruitment in postcapillary venules of the cremaster muscle was investigated by intravital microscopy. Under control conditions, i. e., before superfusing CXCL1 or fMLP over the cremaster muscle, only few firmly adherent or transmigrated leukocytes were detected. There was no difference between the two genotypes. Before superfusing CXCL1 we counted $87 \pm 14$ (WT/ $\mathrm{WT})$ and $76 \pm 11$ (WT/TRPC6 ${ }^{-/}$) firmly adherent neutrophils per square millimeter (Fig. 2a). The control numbers of the fMLP group were $63 \pm 18$ and $41 \pm 9$ neutrophils per square millimeter (Fig. 2b), respectively. When the cremaster muscle was superfused for $2 \mathrm{~h}$ with CXCL1, the number of adherent cells rose $\sim 15$-fold in WT/WT mice. In WT/TRPC6 ${ }^{-/}$mice it was clearly lower in comparison to WT/WT animals (decrease by 60\%) (Fig. 2a). Using fMLP, the number of firmly adherent cells rose $\sim 11$ fold, but there was no difference between WT/WT and WT/TRPC6 ${ }^{-/}$mice (Fig. 2b). Similar results were observed for transmigrated cells. When superfusing CXCL1, the number of transmigrated cells was $41 \%$ lower in WT/TRPC6 ${ }^{-1-}$ mice than in WT/WT mice. Stimulation with fMLP elicited no difference between WT/WT and WT/TRPC6 ${ }^{-1-}$ mice (Fig. 2c).

In the next set of experiments, we tested the acute effect of an intravascular injection of CXCL1 on neutrophil arrest. The number of adherent neutrophils under control conditions is represented by the value at $t=0 \mathrm{~min}$ in Fig. $2 \mathrm{~d}$. Prior to the injection of CXCL1 or fMLP (corresponding to $t=0$ ), the number of arrested and tightly adherent neutrophils amounted to $48 \pm 10$ and $40 \pm 4$ cells $/ \mathrm{mm}^{2}$ in WT/WT and WT/TRPC6 ${ }^{-1}$ - mice, respectively (Fig. 2d). Intravascular arrest of neutrophils remained almost unchanged in WT/TRPC6 ${ }^{-/}$in comparison with WT/WT mice. In WT/WT mice, the number of firmly arrested neutrophils rose more than 6-fold (Fig. 2c). This indicates that TRPC6 channels play a prominent role in neutrophil adhesion on endothelial cells. TRPC6 channels are crucial for CXCL1-triggered adhesion.

\section{TRPC6 regulates $\mathrm{Ca}^{2+}$ signaling after initial selectin contact of neutrophils}

The intracellular $\mathrm{Ca}^{2+}$ mobilization after initial contact of neutrophils with selectins was analyzed in flow chambers coated with E-selectin and CXCL1. During rolling and initial selectin contact, $\left[\mathrm{Ca}^{2+}\right]_{\mathrm{i}}$ increased up to $1100 \mathrm{nM}$ in WT neutrophils, but only up to $700 \mathrm{nM}$ in TRPC6 ${ }^{-/}$cells (see Fig. $3 \mathrm{a}$ ). $\left[\mathrm{Ca}^{2+}\right]_{\mathrm{i}}$ returned to baseline levels of 100-200 $\mathrm{nM}$ within a few minutes. We only analyzed the changes of $\left[\mathrm{Ca}^{2+}\right]_{\mathrm{i}}$ observed during the first $5 \mathrm{~s}$ after initial selectin contact in detail in order to avoid a confounding effect of integrin-mediated outside-in 

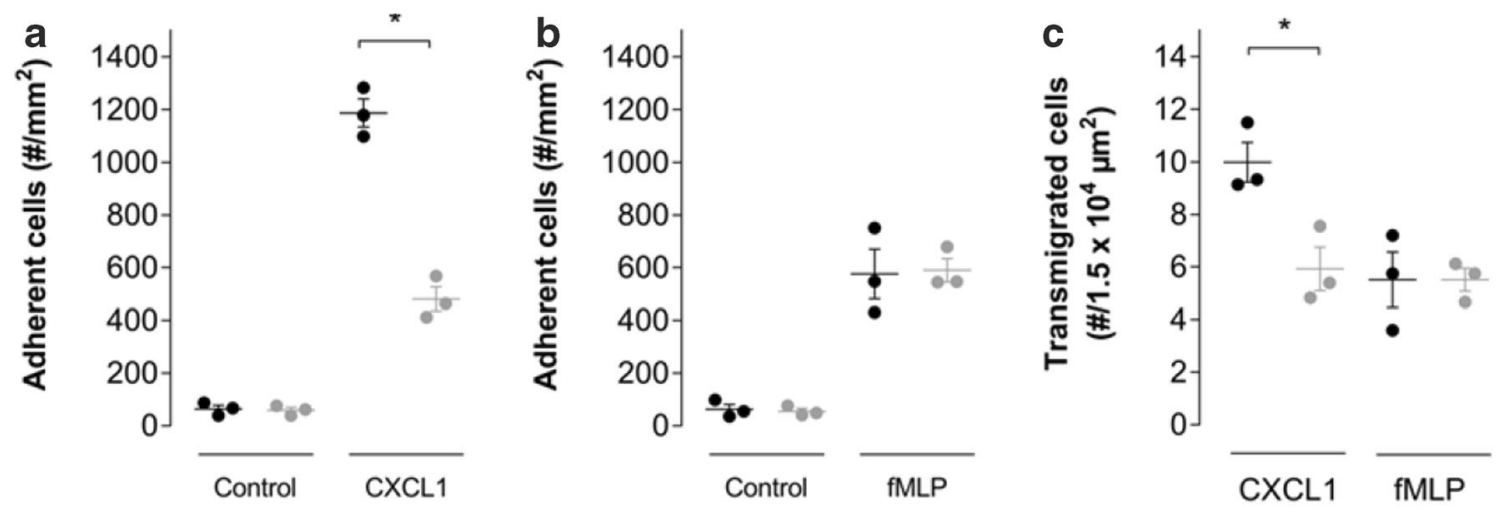

\section{- WT/WT $\bullet$ WT/TRPC6-l-}

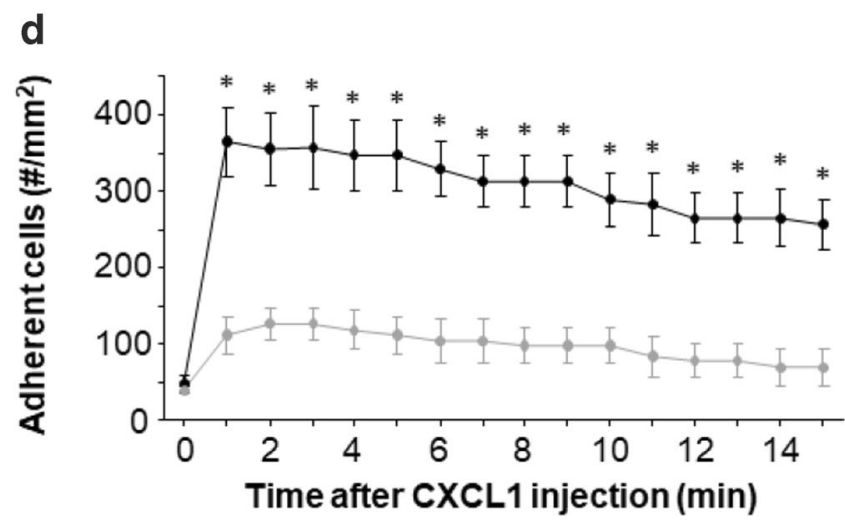

Fig. 2 Inflammatory recruitment of neutrophils is impaired in WT/ TRPC $^{-/-}$mice. The number of arrested, tightly adherent $(\mathbf{a}, \mathbf{b})$ and transmigrated (c) leukocytes in postcapillary venules of the cremaster muscle of WT/WT and WT/TRPC6 ${ }^{-1}$ mice were analyzed by intravital microscopy. Arrest and transmigration of neutrophils were induced by superfusing the cremaster muscle with CXCL1 or fMLP containing

signaling in neutrophils that might have resulted from an interaction with the cell culture treated surface of the flow chambers. Using a similar microfluidic approach, it had been shown that an LFA1-induced increase of $\left[\mathrm{Ca}^{2+}\right]_{i}$ occurs only after a lag period of more than $40 \mathrm{~s}[41]$. The $\left[\mathrm{Ca}^{2+}\right]_{\mathrm{i}}$ integral was $39 \%$ smaller in TRPC $^{-/-}$neutrophils than in WT cells (see Fig. 3b).

To distinguish between a CXCL1- or E-selectin-triggered increase in $\left[\mathrm{Ca}^{2+}\right]_{i}$, we repeated these experiments with flow chambers that were coated with E-selectin only. These experiments were complicated by the fact that the number of firmly adherent neutrophils was largely reduced and the vast majority of cells rolled out of the visual filed within a few seconds so that the measurements could not be calibrated. Consequently, $\left[\mathrm{Ca}^{2+}\right]_{\mathrm{i}}$ was assessed qualitatively in form of the ratio $F_{340} /$ $F_{380}$. As evident from Fig. $3 \mathrm{c}$ and d, neutrophils from WT and $\mathrm{TRPC}^{-/-}$mice behave alike. This is consistent with TRPC6 channels being required for the CXCL1-induced rise of $\left[\mathrm{Ca}^{2+}\right]_{\mathrm{i}}$.
Ringer's solution for $2 \mathrm{~h}$. (d) Intravascular injection of CXCL1 induces an immediate chemokine-induced leukocyte arrest in WT/WT mice but not in WT/TRPC6 ${ }^{-1-}$ mice ( $N=4$ mice/group). The value at $t=0$ reflects the control conditions prior to the injection of CXCL1. Values are reported as mean values \pm SEM. $* p<0.05$

\section{TRPC6 activates CXCL1-mediated adhesion of neutrophils}

Adhesion forces between neutrophils and endothelial cells were quantified with single-cell force spectroscopy using atomic force microscopy (Fig. 4a). To mimic the rapid time course of intravascular adhesion, neutrophils adhering to the AFM cantilever were placed onto an endothelial cell for only $1 \mathrm{~s}$ with a force of $1 \mathrm{nN}$. Then, the cantilever was lifted and maximum adhesion forces between endothelial cells and neutrophils were measured (Fig. 4b). Stimulation with both CXCL1 and fMLP increased adhesion forces in WT neutrophils (Fig. 4c). In TRPC6 ${ }^{-/-}$neutrophils, stimulation with CXCL1 had no effect, while fMLP could still elicit an increase in the adhesion forces to a level that was even $25 \%$ higher than in WT neutrophils. These data show that CXCL1-mediated adhesion is controlled by TRPC 6 channels and that TRPC ${ }^{-1}$ - neutrophils do not have a global defect in responding to chemoattractant stimulation. Moreover, they are in line with 

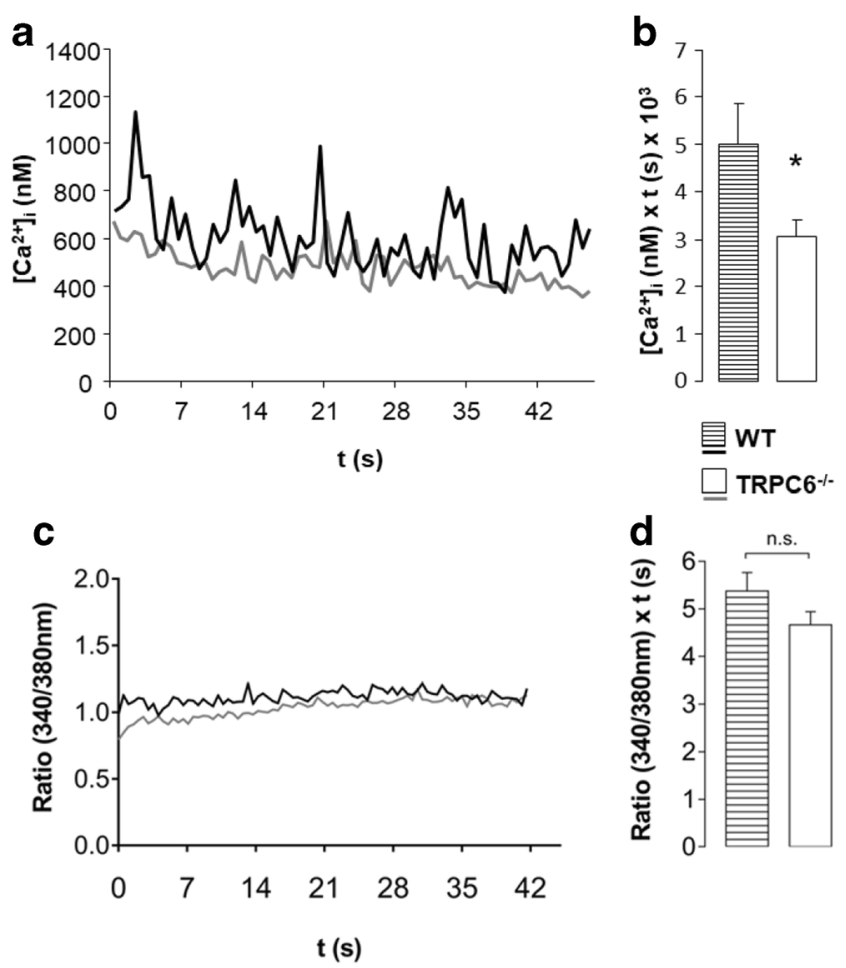

Fig. $3\left[\mathrm{Ca}^{2+}\right]_{\mathrm{i}}$ concentration after initial selectin contact is decreased in TRPC6 ${ }^{-} \digamma$ neutrophils. Mean $\left[\mathrm{Ca}^{2+}\right]_{\mathrm{i}}$ response of $\mathrm{WT}$ and TRPC6 ${ }^{-/-}$ neutrophils after initial contact to a surface coated with E-selectin and CXCL1 (a) and corresponding integrals of the $\left[\mathrm{Ca}^{2+}\right]_{\mathrm{I}}$ for the first $5 \mathrm{~s}(\mathbf{b})$ ( $n \geq 52$ cells, $N \geq 3$ mice). (c) Same experiment as in a, except that the surface is coated only with E-selectin and the corresponding integrals of the $\left[\mathrm{Ca}^{2+}\right]_{\mathrm{i}}$ for the first $5 \mathrm{~s}$ (d) $(n \geq 43$ cells, $N \geq 3$ mice $)$. Values are reported as mean values \pm SEM. $* p<0.05$

our findings described above showing the requirement of TRPC6 channels for CXCL1-triggered adhesion of neutrophils to postcapillary venules.

Experiments with single-cell force spectroscopy were complemented with a microfluidic adhesion assay with Eselectin-coated flow chambers in which CXCL1 and fMLP were tested at different concentrations (Fig. 4d, e). Maximum adhesion of neutrophils from both genotypes was achieved with $3 \mu \mathrm{g} / \mu \mathrm{l} \mathrm{CXCL1}$; lower and higher CXCL1 concentrations elicited less adhesion. However, at the optimal CXCL1 concentration there were $\sim 50 \%$ more adherent WT neutrophils than adherent TRPC $6^{-/-}$neutrophils. When neutrophils were stimulated with AMLP, there was no significant difference between the two genotypes at any of the tested concentrations (Fig. 4e).

The role of TRPC6 channels in CXCL1-induced adhesion of neutrophils was further corroborated by performing in vitro adhesion assays in the absence and presence of the TRPC6 channel blocker larixyl acetate [42]. In the presence of $5 \mu \mathrm{mol} / \mathrm{L}$ larixyl acetate, CXCL1 ( $3 \mu \mathrm{g} / \mu \mathrm{l})$ failed to increase the number of adherent WT neutrophils (Fig. 4d). It remained at the same level as observed for TRPC $6^{-/-}$neutrophils.
CXCR2-mediated Rap1 activation depends on TRPC6 channels

The small GTPase Rap1 (Ras-related protein 1) has been shown to be involved in $\mathrm{Ca}^{2+}$ dependent integrin activation $[26,43]$. Rap1-regulated adhesion of WT and TRPC $6^{-1-}$ neutrophils was analyzed with TAT-fusion mutants of Rap1 in a microflow chamber assay (Fig. 5a). TAT-coupled Rap1-WT served as control, and a TAT-coupled constitutively active mutant of Rap1 (TAT-Rap1-CA) was used to activate integrin-mediated adhesion of the cells. In the absence of CXCL1, WT and TRPC6 ${ }^{-/-}$neutrophils treated with the TatRap1-WT peptide adhered poorly in flow chambers coated with P-selectin/ICAM-1. The constitutively active mutant TAT-Rap1-CA elicited a robust increase in the number of adherent neutrophils of both genotypes. Similarly, the presence of the chemokine CXCL1 in the flow chambers induced a strong rise in the number of adherent WT neutrophils. Treatment of WT neutrophils with the mutant TAT-Rap1-CA had no additional effect. In contrast, CXCL1 failed to increase adhesion of $\mathrm{TRPC}^{-/-}$neutrophils. This defect could be rescued by pretreating TRPC $6^{-/-}$neutrophils with the constitutively active Tat-Rap1-CA peptide.

Rap1 activation was analyzed in Rap1 pull-down assays. After CXCL1 stimulation, the amount of active Rap1 protein was $\sim 30 \%$ lower in TRPC $^{-/-}$than in WT neutrophils (Fig. $5 b)$. These findings suggest that TRPC 6 channels regulate the CXCR2-mediated adhesion of neutrophils by activating Rap1. Accordingly, the adhesion defect of TRPC $6^{-/-}$neutrophils can be rescued by treating them with a constitutively active Rap1 protein.

Taken together, our results are consistent with the notion that Rap1 activation triggered downstream signaling leading to a conformational switch of $\beta_{2}$-integrins to the high affinity conformation necessary for firm adhesion. The constitutively active Rap1 is able to overcome the functional defect of $\mathrm{TRPC}^{-/-}$neutrophils. Thus, these results provide indirect evidence for a link between TRPC6 channels and Rap1.

\section{ICAM-1 binding after CXCR2 activation is reduced in $\mathrm{TRPC}^{-/-}$neutrophils}

Intravascular firm adhesion of neutrophils is mediated by the activated $\beta_{2}$-integrin LFA-1 [6]. Integrin activation can be assessed by quantifying ICAM-1 binding by neutrophils. In order to determine LFA-1 dependent ICAM-1 binding, neutrophils were pretreated with a blocking Mac-1 antibody because Mac-1 is the only other binding partner of ICAM- 1 on neutrophils [44]. ICAM-1 binding was measured under control conditions or after 3 min of CXCL1 stimulation by flow cytometry (Fig. 6). Under control conditions, the ICAM-1 binding was low, and no difference could be detected between WT and TRPC $^{-/-}$neutrophils. After CXCL1 stimulation, ICAM-1 
Fig. 4 Neutrophil adhesion is decreased by loss of TRPC6.

Experimental setup for single cell force spectroscopy (a), representative force-distance curves of neutrophils stimulated with CXCL1 and adhering to endothelial cells (b), and summary of force spectroscopy of neutrophils (c) ( $n \geq 5$ neutrophils from $N \geq 3$ mice. Adhesion measurements were performed on 10 endothelial cells per neutrophil attached to the cantilever). (d) Summary of a microfluidic adhesion assay in which the number of CXCL1-stimulated WT and TRPC6 $6^{-1-}$ neutrophils adhering to an E-selectin-coated flow chambers was quantified (larixyl: $5 \mu \mathrm{mol} / \mathrm{L}$ larixyl acetate; $N=5$ mice for each genotype). $\mathrm{e}$ Summary of a microfluidic adhesion assay in which the number of fMLP-stimulated WT and TRPC $6^{-1-}$ neutrophils adhering to an E-selectin coated flow chambers was quantified (neutrophils from $N=3 \mathrm{WT}$ mice and $N=4$ TRPC $^{-/-}$mice). Values are reported as mean values \pm SEM. $* p<0.05$
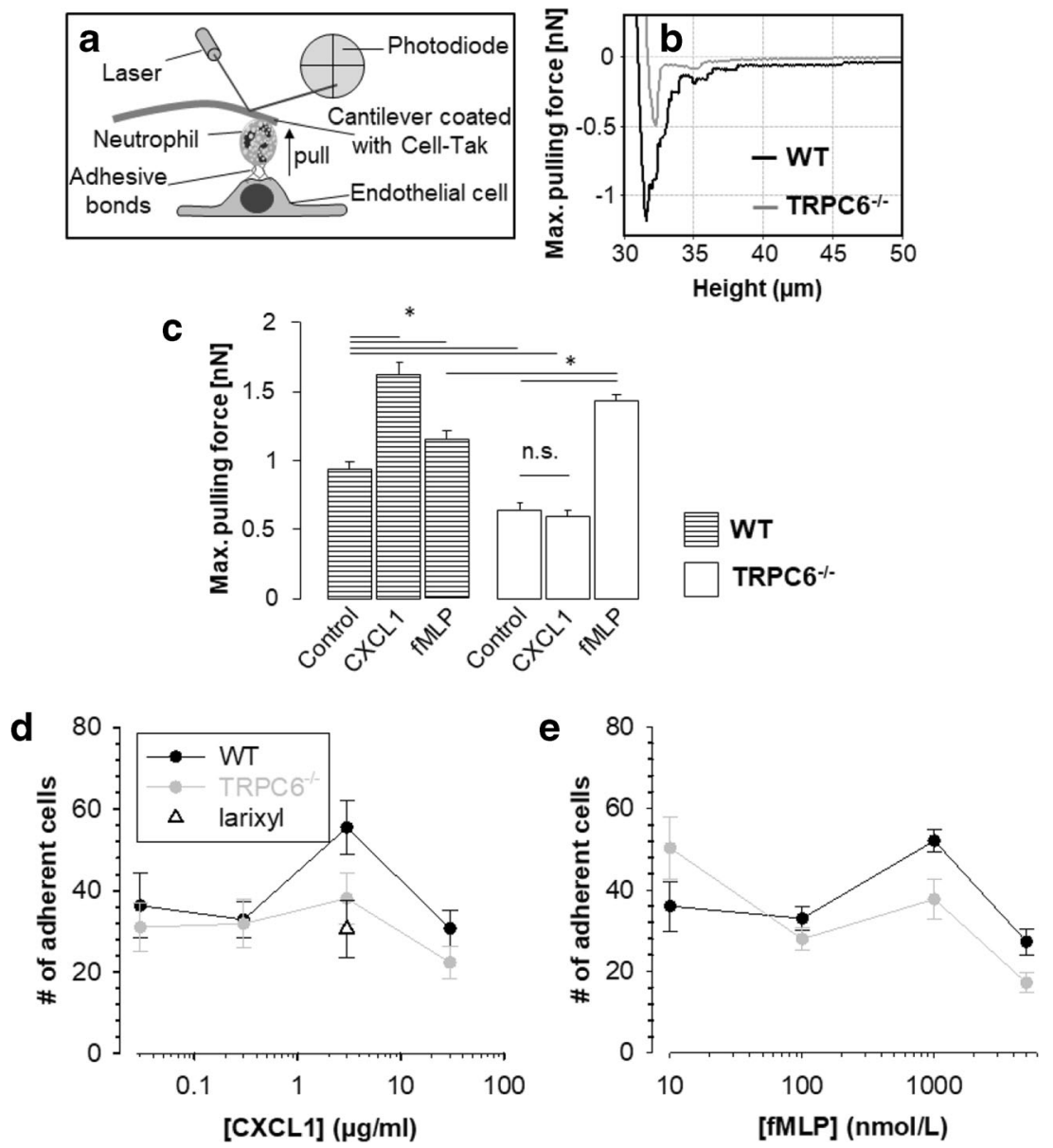

binding increased in both cell types. However, the rise was 4.6fold higher in WT than in TRPC6 ${ }^{-/}$neutrophils. The strong TRPC6-dependent increase in ICAM-1 binding can be attributed to LFA1 because Mac1 was functionally blocked in these experiments. These results lend further support to the involvement of TRPC6 channels in CXCR2-induced LFA-1 activation.

\section{Discussion}

During an inflammation, chemoattractants trigger intracellular signaling cascades in neutrophils that usually involve intracellular $\mathrm{Ca}^{2+}$ transients. While the molecular identity of the underlying $\mathrm{Ca}^{2+}$-permeable channels has begun to be unraveled (reviewed in $[16,17]$ ), their functional roles in the steps of the neutrophil recruitment cascade and their effector proteins have not yet been clarified in detail.

We previously demonstrated that TRPC6 channels are crucial for neutrophil chemotaxis in a collagen gel [12]. Similarly, eosinophil recruitment during an allergic airway response requires TRPC6 channels. The latter was hypothesized to be due to TRPC6 induced non-store operated $\mathrm{Ca}^{2+}$ influx and $\beta_{2^{-}}$ integrin activation $[45,46]$. On the other hand, deletion of
TRPC6 channels confers renoprotection in a model of nephrosis. This is also associated with a reduced number of infiltrating monocytes and macrophages [47]. It was also shown that endothelial TRPC6 channels are needed for neutrophil recruitment [19]. In our previous study [12], we could not distinguish whether TRPC6 channels expressed in neutrophils or endothelial cells are needed for the recruitment to the peritoneal cavity because we used a global TRPC6 $6^{-/}$mouse model. By employing chimeric mice with bone marrow cells from TRPC6 $^{-1-}$ mice, we can now clearly state that TRPC6 channels in neutrophils are essential for their CXCR2-dependent recruitment from the blood stream.

The present study shows that TRPC6 channels in neutrophils are essential for CXCR2-mediated transendothelial recruitment. This conclusion is based on the following key results: (1) firm intravascular adhesion and transmigration of neutrophils in vivo requires TRPC6 channels; (2) renal damage and neutrophil recruitment were diminished in the WT/ TRPC6 $^{-1-}$ chimeras after a renal ischemia/reperfusion injury; (3) the increase of $\left[\mathrm{Ca}^{2+}\right]_{i}$ after initial contact to an E-selectin and CXCL1-coated surface is partially dependent on TRPC6 channels; E-selectin coating alone elicits no TRPC6dependent $\mathrm{Ca}^{2+}$ signals; (4) CXCR2-induced adhesion of neutrophils to E-selectin-coated surfaces and to endothelial cells 
a
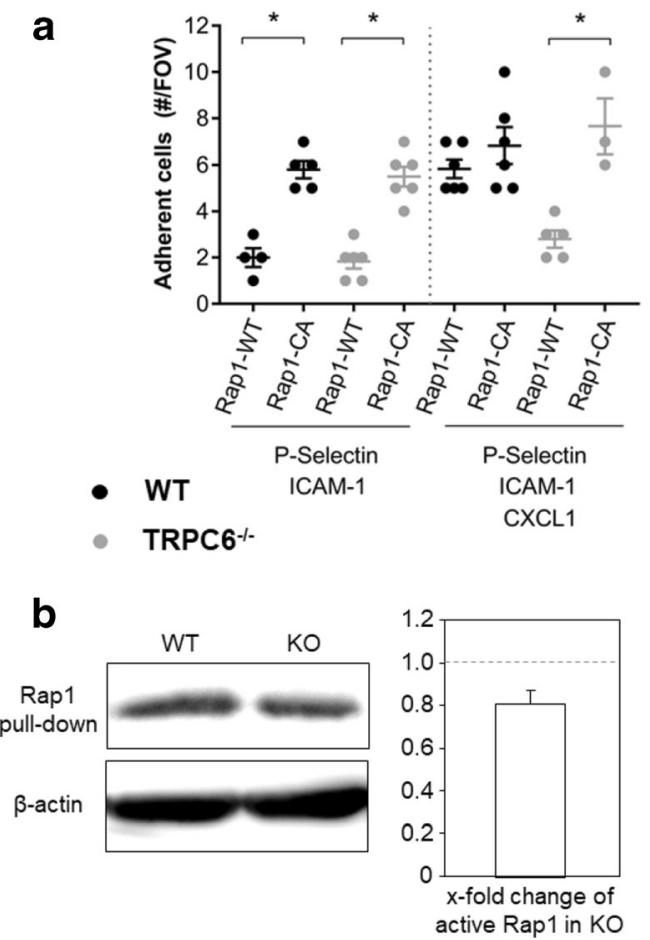

Fig. 5 Chemoattractant-mediated Rap1 activation depends on TRPC6 channels. (a) Effect of WT or constitutive active Rap1 Tat-fusion mutants on neutrophil adhesion under flow \pm CXCL1 stimulation ( $n \geq 3$ experiments from $N \geq 3$ mice). Values are reported as mean values \pm SEM. ${ }^{*} p<0.05$. (b) Western blot analysis of active Rap1 after CXCL1 stimulation. For densiometric quantification of $\mathrm{x}$-fold change in protein expression, equal loading was normalized to expression of $\beta$-actin. Values are reported as mean values $\pm \mathrm{SEM}$ from $N=3$ experiments with neutrophil lysates pooled from two mice for each experiment

requires TRPC6 channels; (5) Rap1-induced neutrophil adhesion and LFA1-mediated ICAM-1 binding depend on TRPC6 channels.

In our previous study, we had demonstrated that TRPC6 deficiency leads to impaired $\mathrm{Ca}^{2+}$ signaling after CXCR2 stimulation of neutrophils [12]. This was recapitulated in the present study under more physiological conditions. The rise of $\left[\mathrm{Ca}^{2+}\right]_{\mathrm{i}}$ after initial selectin contact and CXCR2 activation was also significantly lower in TRPC6 ${ }^{-1-}$ than in WT neutrophils. This TRPC6-dependent rise of $\left[\mathrm{Ca}^{2+}\right]_{\mathrm{i}}$ occurred much faster than the one involving integrin signaling [41]. The most likely explanation is that CXCR2 triggers the activation of TRPC6 via PLC $\beta$-mediated DAG production [48]. In our view, this attenuation of $\mathrm{Ca}^{2+}$ transients in TRPC ${ }^{-/}$neutrophils is likely to have implications for further downstream targets involved in the activation of integrins. CalDAG-GEF1 is activated by DAG and $\mathrm{Ca}^{2+}$, the latter with a $\mathrm{K}_{\mathrm{D}}$ of $1.3 \mu \mathrm{mol} / 1$ [49]. This value is exactly in the range of the $\left[\mathrm{Ca}^{2+}\right]_{\mathrm{i}}$ elevations observed in rolling WT neutrophils in our experiments. In TRPC $^{-/-}$neutrophils, $\left[\mathrm{Ca}^{2+}\right]_{\mathrm{i}}$ only rises to $700 \mathrm{nmol} / \mathrm{L}$. We can therefore assume that CalDAG-GEF1 is not fully activated in TRPC6 ${ }^{-1}$ neutrophils. This could be an explanation for our findings that CXCR2-mediated Rap1 activation depends on TRPC6 channels because Rap1 is a downstream target of CalDAG-GEF1. Importantly and in line with our findings, Rap1 is involved in $\beta_{2}$-integrin-mediated slow rolling of neutrophils [26, 43]. Thus, we propose that the TRPC6-mediated rise of $\left[\mathrm{Ca}^{2+}\right]_{\mathrm{i}}$ links the activation of CXCR2 indirectly to Rap1 stimulation (Fig. 7) which initiates the activation of LFA1 or Mac1 by its interaction with Talin1 and RIAM (Rap1-GTP-interacting adapter molecule) [50, 51]. The fact that the rise of $\left[\mathrm{Ca}^{2+}\right]_{\mathrm{i}}$ is not completely abolished in TRPC6 ${ }^{-1}$ - neutrophils is also reflected by our results. Both the activation of Rap1 and the increase in ICAM-1 binding upon CXCL1 stimulation are attenuated in TRPC6 ${ }^{-/}$neutrophils but not completely absent. Future studies need to address in a quantitative way whether (TRPC6-dependent) Rap1 activation and neutrophil adhesion are linearly correlated or whether there is a "threshold" of Rap1 activation beyond which neutrophil adhesion is maximal.

Our findings that altered $\mathrm{Ca}^{2+}$ signaling in TRPC6 ${ }^{-/}$neutrophils leads to impaired neutrophil function is in line with
Fig. 6 CXCR2-mediated ICAM1 binding depends on TRPC6 channels. Flow cytometric measurement of ICAM-1 binding to neutrophils ( $N=3$ mice/group). a Representative histograms. For clarity reasons, we only depict the histograms for CXCL1stimulated neutrophils. b Summary of ICAM-1-binding experiments. Values are reported as mean values \pm SEM. $* p<0.05$ a

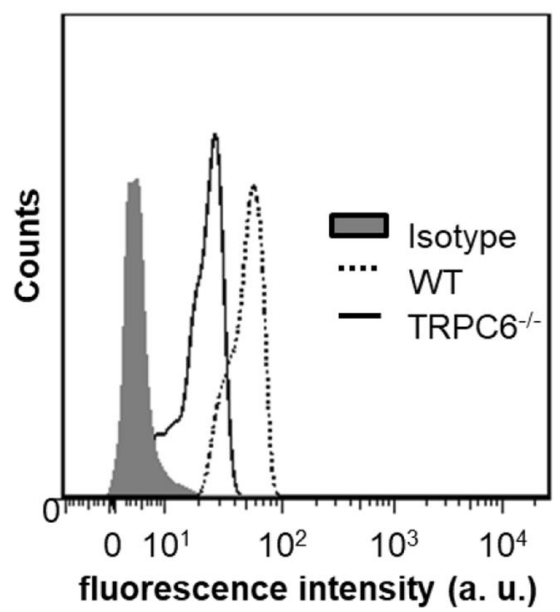

b

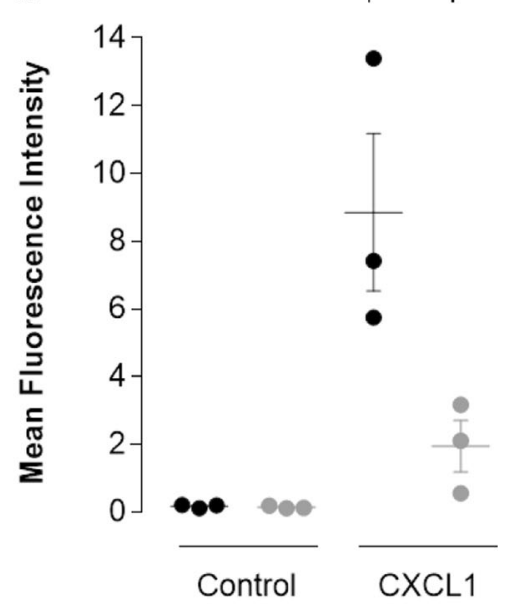




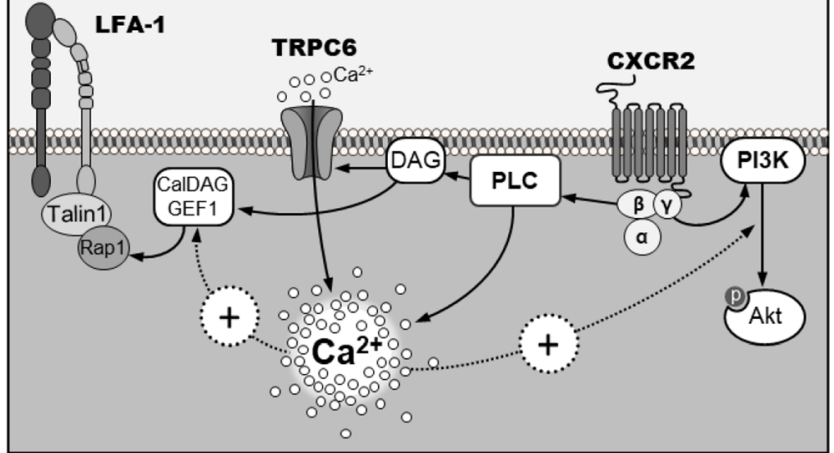

Fig. 7 Integrin activation via CXCR2 and TRPC6. Chemokine binding of CXCR2 activates PLC triggering $\mathrm{Ca}^{2+}$ mobilization via store depletion and TRPC6 channels. This activates CalDAG-GEF1 which in turn activates Rap-1 mobilizing Talin $1-\beta_{2}$ integrin association

other studies that also revealed a critical dependence of neutrophil behavior on $\mathrm{Ca}^{2+}$ signaling. Notably, both an increase and a decrease in the intracellular $\mathrm{Ca}^{2+}$ signals are accompanied by impaired neutrophil function. Increased $\mathrm{Ca}^{2+}$ signals are found in $\mathrm{TRPC}^{-/}$[11] and in CF neutrophils [52]. The affected neutrophils have a defect in chemotaxis and ROS production as well as antimicrobial killing capacity, respectively. Intracellular $\mathrm{Ca}^{2+}$ signaling is attenuated in STIM1 $1^{--}$ neutrophils and linked to impaired chemotaxis and infiltration of psoriatic lesions [53]. TRPV4 ${ }^{-/-}$neutrophils exhibit reduced $\mathrm{Ca}^{2+}$ transients following stimulation with PAF or 5,6-EET. Consequences are reduced ROS production, neutrophil adhesion, and chemotaxis [15].

Interestingly, neutrophils that are deficient for the actinbinding protein HS1 have the same complex phenotype as TRPC $^{-1-}$ neutrophils which we described in this and our previous paper $[12,54]$ : CXCL1-stimulated adhesion, transmigration, initial arrest, and recruitment into the inflamed peritoneal cavity are impaired. Moreover, $\mathrm{HS}^{-/-}$neutrophils share the same defect in chemotaxis with TRPC $6^{-/-}$neutrophils, while migration itself is also largely unaffected. Mechanistically, the phenotype of $\mathrm{HS}^{-/-}$neutrophils could be linked to a reduced Rap1 activation. In our view, these striking parallels lend support to the notion that TRPC6- as well as HS1-dependent and CXCL1-triggered signaling pathways utilize Rap1 as the same downstream effector protein.

We could show in a quantitative manner that chemoattractant receptor activation leads to doubling of adhesion forces of neutrophils adhering to endothelial cells. These findings are in good agreement with our dynamic assays using microfluidic devices. Nonetheless, single-cell spectroscopy provides detailed additional information. It allows the quantification of forces required for single unbinding events [55]. This makes the single-cell force spectroscopy a powerful tool to quantitatively analyze and compare adhesion characteristics of cells adhering to different surfaces.

In conclusion, our data show an important role for TRPC6 channels in transendothelial, CXCL1-triggered recruitment of neutrophils. TRPC6 channels are mediators of CXCL1induced $\mathrm{Ca}^{2+}$ mobilization, which is essential for integrin activation during the first steps of neutrophil recruitment. Thereby, CXCR2-mediated activation of integrins is tightly regulated by TRPC6 channels. This study shows that TRPC6 channels could be interesting therapeutic targets for the pharmacological inhibition during inflammatory diseases involving CXCR2. In patients with acute kidney injury or in diseases like chronic obstructive pulmonary disease (COPD) which are based on the excessive CXCR2-driven recruitment of neutrophils [56], TRPC6 channel inhibition could represent a mild therapeutic approach with fewer side effects that improves patient outcome without completely downregulating the neutrophil function. Similarly, the CXCR2-dependent recruitment of neutrophil granulocytes to the stroma of pancreatic cancer where they elicit high immunosuppressive activity and drive disease progression [57] could potentially be targeted by TRPC6 blockers.

Acknowledgements Open Access funding provided by Projekt DEAL.

Author contribution Contribution: O. L., J. R., K. N., V. H., M. W., and S. S. performed the experiments; O. L., J. R., K. N., S. S. and V. H. analyzed results and made the figures; O. L., J. R., A. Z., B. F., H. O., and A. S. designed the research and wrote the paper.

Funding information This work was supported by grants from the Deutsche Forschungsgemeinschaft (DFG) to H.O. (Reinhart Koselleck program), A. S. (SCHW407/17-1), A. Z. (ZA-428/6-2, SFB1009_A05), J. R. (RO 4537/2-1, RO 4537/3-1), from IZKF Münster to A. S. (S̈chw2/ 020/18). K. N. was supported by a fellowship from the CIM-IMPRS graduate school.

\section{Compliance with ethical standards}

Ethical approval All animal experiments were performed in accordance with institutional and national guidelines and after obtaining the respective permits from the local authorities.

Conflict of interest The authors declare that they have no competing and non-financial conflict of interests.

Open Access |This article is licensed under a Creative Commons Attribution 4.0 International License, which permits use, sharing, adaptation, distribution and reproduction in any medium or format, as long as you give appropriate credit to the original author(s) and the source, provide a link to the Creative Commons licence, and indicate if changes were made. The images or other third party material in this article are included in the article's Creative Commons licence, unless indicated otherwise in a credit line to the material. If material is not included in the article's Creative Commons licence and your intended use is not permitted by statutory regulation or exceeds the permitted use, you will need to obtain permission directly from the copyright holder. To view a copy of this licence, visit http://creativecommons.org/licenses/by/4.0/.

\section{References}

1. Filippi MD (2019) Neutrophil transendothelial migration: updates and new perspectives. Blood. https://doi.org/10.1182/blood-2018$12-844605$ 
2. Stadtmann A, Germena G, Block H, Boras M, Rossaint J, Sundd P, Lefort C, Fisher CI, Buscher K, Gelschefarth B, Urzainqui A, Gerke V, Ley K, Zarbock A (2013) The PSGL-1-L-selectin signaling complex regulates neutrophil adhesion under flow. J Exp Med 210(11):2171-2180

3. Marki A, Esko JD, Pries AR, Ley K (2015) Role of the endothelial surface layer in neutrophil recruitment. J Leukoc Biol 98(4):503515

4. Lomakina EB, Waugh RE (2010) Signaling and dynamics of activation of LFA-1 and Mac-1 by immobilized IL-8. Cell Mol Bioeng $3(2): 106-116$

5. Lefort CT, Rossaint J, Moser M, Petrich BG, Zarbock A, Monkley SJ, Critchley DR, Ginsberg MH, Fassler R, Ley K (2012) Distinct roles for talin-1 and kindlin-3 in LFA-1 extension and affinity regulation. Blood 119(18):4275-4282

6. Phillipson M, Heit B, Colarusso P, Liu L, Ballantyne CM, Kubes P (2006) Intraluminal crawling of neutrophils to emigration sites: a molecularly distinct process from adhesion in the recruitment cascade. J Exp Med 203(12):2569-2575

7. Wu D, LaRosa GJ, Simon MI (1993) G protein-coupled signal transduction pathways for interleukin-8. Science 261(5117):101103

8. Schaff UY, Dixit N, Procyk E, Yamayoshi I, Tse T, Simon SI (2010) Orai1 regulates intracellular calcium, arrest, and shape polarization during neutrophil recruitment in shear flow. Blood 115(3):657-666

9. Hofmann T, Obukhov AG, Schaefer M, Harteneck C, Gudermann T, Schultz G (1999) Direct activation of human TRPC6 and TRPC3 channels by diacylglycerol. Nature 397(6716):259-263

10. Sogkas G, Vogtle T, Rau E, Gewecke B, Stegner D, Schmidt RE, Nieswandt B, Gessner JE (2015) Orail controls C5a-induced neutrophil recruitment in inflammation. Eur J Immunol 45(7):21432153

11. Lindemann O, Strodthoff C, Horstmann M, Nielsen N, Jung F, Schimmelpfennig S, Heitzmann M, Schwab A (2015) TRPC1 regulates fMLP-stimulated migration and chemotaxis of neutrophil granulocytes. Biochim Biophys Acta 1853(9):2122-2130

12. Lindemann O, Umlauf D, Frank S, Schimmelpfennig S, Bertrand J, Pap T, Hanley PJ, Fabian A, Dietrich A, Schwab A (2013) TRPC6 regulates CXCR2-mediated chemotaxis of murine neutrophils. J Immunol 190(11):5496-5505

13. Damann N, Owsianik G, Li S, Poll C, Nilius B (2009) The calciumconducting ion channel transient receptor potential canonical 6 is involved in macrophage inflammatory protein-2-induced migration of mouse neutrophils. Acta Physiol (Oxford) 195(1):3-11

14. Yamamoto S, Shimizu S, Kiyonaka S, Takahashi N, Wajima T, Hara Y, Negoro T, Hiroi T, Kiuchi Y, Okada T, Kaneko S, Lange I, Fleig A, Penner R, Nishi M, Takeshima H, Mori Y (2008) TRPM2-mediated $\mathrm{Ca}^{2+}$ influx induces chemokine production in monocytes that aggravates inflammatory neutrophil infiltration. Nat Med 14(7):738-747

15. Yin J, Michalick L, Tang C, Tabuchi A, Goldenberg N, Dan Q, Awwad K, Wang L, Erfinanda L, Nouailles G, Witzenrath M, Vogelzang A, Lv L, Lee WL, Zhang H, Rotstein O, Kapus A, Szaszi K, Fleming I, Liedtke WB, Kuppe H, Kuebler WM (2016) Role of transient receptor potential vanilloid 4 in neutrophil activation and acute lung injury. Am J Respir Cell Mol Biol 54(3):370383

16. Najder K, Musset B, Lindemann O, Bulk E, Schwab A, Fels B (2018) The function of TRP channels in neutrophil granulocytes. Pflugers Arch 470(7):1017-1033

17. Immler R, Simon SI, Sperandio M (2018) Calcium signalling and related ion channels in neutrophil recruitment and function. Eur $\mathrm{J}$ Clin Invest 48(Suppl 2):e12964

18. Earley S, Brayden JE (2015) Transient receptor potential channels in the vasculature. Physiol Rev 95(2):645-690
19. Weber EW, Han F, Tauseef M, Birnbaumer L, Mehta D, Muller WA (2015) TRPC6 is the endothelial calcium channel that regulates leukocyte transendothelial migration during the inflammatory response. J Exp Med 212(11):1883-1899

20. Chen QZ, Zhou YB, Zhou LF, Fu ZD, Wu YS, Chen Y, Li SN, Huang JR, Li JH (2019) TRPC6 modulates adhesion of neutrophils to airway epithelial cells via NF-kappaB activation and ICAM-1 expression with ozone exposure. Exp Cell Res 377(1-2):56-66

21. Mittal M, Nepal S, Tsukasaki Y, Hecquet CM, Soni D, Rehman J, Tiruppathi C, Malik AB (2017) Neutrophil activation of endothelial cell-expressed TRPM2 mediates transendothelial neutrophil migration and vascular injury. Circ Res 121(9):1081-1091

22. Ramirez GA, Coletto LA, Sciorati C, Bozzolo EP, Manunta P, Rovere-Querini P, Manfredi AA (2018) Ion channels and transporters in inflammation: special focus on TRP channels and TRPC6. Cells 7(7). https://doi.org/10.3390/cells 7070070

23. Zarbock A, Deem TL, Burcin TL, Ley K (2007) $\mathrm{G} \alpha_{\mathrm{i} 2}$ is required for chemokine-induced neutrophil arrest. Blood 110(10):37733779

24. Cook AA, Deng W, Ren J, Li R, Sondek J, Bergmeier W (2018) Calcium-induced structural rearrangements release autoinhibition in the Rap-GEF CalDAG-GEFI. J Biol Chem 293(22):8521-8529

25. Bergmeier W, Goerge T, Wang HW, Crittenden JR, Baldwin AC, Cifuni SM, Housman DE, Graybiel AM, Wagner DD (2007) Mice lacking the signaling molecule CalDAG-GEFI represent a model for leukocyte adhesion deficiency type III. J Clin Invest 117(6): $1699-1707$

26. Ghandour H, Cullere X, Alvarez A, Luscinskas FW, Mayadas TN (2007) Essential role for Rap1 GTPase and its guanine exchange factor CalDAG-GEFI in LFA-1 but not VLA-4 integrin mediated human T-cell adhesion. Blood 110(10):3682-3690

27. Kilic SS, Etzioni A (2009) The clinical spectrum of leukocyte adhesion deficiency (LAD) III due to defective CalDAG-GEF1. J Clin Immunol 29(1):117-122

28. Zarbock A, Singbartl K, Ley K (2006) Complete reversal of acidinduced acute lung injury by blocking of platelet-neutrophil aggregation. J Clin Invest 116(12):3211-3219

29. Block H, Stadtmann A, Riad D, Rossaint J, Sohlbach C, Germena G, Wu D, Simon SI, Ley K, Zarbock A (2016) Gnb isoforms control a signaling pathway comprising Rac1, PLC $\beta 2$, and PLC $\beta 3$ leading to LFA-1 activation and neutrophil arrest in vivo. Blood 127(3):314-324

30. Zarbock A, Abram CL, Hundt M, Altman A, Lowell CA, Ley K (2008) PSGL-1 engagement by E-selectin signals through Src kinase Fgr and ITAM adapters DAP12 and FcR gamma to induce slow leukocyte rolling. J Exp Med 205(10):2339-2347

31. Mempel TR, Moser C, Hutter J, Kuebler WM, Krombach F (2003) Visualization of leukocyte transendothelial and interstitial migration using reflected light oblique transillumination in intravital video microscopy. J Vasc Res 40(5):435-441

32. Zarbock A, Lowell CA, Ley K (2007) Spleen tyrosine kinase Syk is necessary for E-selectin-induced alpha(L)beta(2) integrin-mediated rolling on intercellular adhesion molecule-1. Immunity 26(6):773783

33. Lipowsky HH, Zweifach BW (1978) Application of the "two-slit" photometric technique to the measurement of microvascular volumetric flow rates. Microvasc Res 15(1):93-101

34. Long DS, Smith ML, Pries AR, Ley K, Damiano ER (2004) Microviscometry reveals reduced blood viscosity and altered shear rate and shear stress profiles in microvessels after hemodilution. Proc Natl Acad Sci U S A 101(27):10060-10065

35. Storck H, Hild B, Schimmelpfennig S, Sargin S, Nielsen N, Zaccagnino A, Budde T, Novak I, Kalthoff H, Schwab A (2017) Ion channels in control of pancreatic stellate cell migration. Oncotarget 8(1):769-784 
36. Hofschroer V, Koch KA, Ludwig FT, Friedl P, Oberleithner H, Stock C, Schwab A (2017) Extracellular protonation modulates cell-cell interaction mechanics and tissue invasion in human melanoma cells. Sci Rep 7:42369

37. Frankel AD, Pabo CO (1988) Cellular uptake of the tat protein from human immunodeficiency virus. Cell 55(6):1189-1193

38. Bolomini-Vittori M, Montresor A, Giagulli C, Staunton D, Rossi B, Martinello M, Constantin G, Laudanna C (2009) Regulation of conformer-specific activation of the integrin LFA-1 by a chemokine-triggered Rho signaling module. Nat Immunol 10(2): 185-194

39. Kuwano Y, Spelten O, Zhang H, Ley K, Zarbock A (2010) Rolling on E- or P-selectin induces the extended but not high-affinity conformation of LFA-1 in neutrophils. Blood 116(4):617-624

40. Jakob SM, Pick R, Brechtefeld D, Nussbaum C, Kiefer F, Sperandio M, Walzog B (2013) Hematopoietic progenitor kinase 1 (HPK1) is required for LFA-1-mediated neutrophil recruitment during the acute inflammatory response. Blood 121(20):41844194

41. Dixit N, Yamayoshi I, Nazarian A, Simon SI (2011) Migrational guidance of neutrophils is mechanotransduced via high-affinity LFA-1 and calcium flux. J Immunol 187(1):472-481

42. Urban N, Wang L, Kwiek S, Rademann J, Kuebler WM, Schaefer M (2016) Identification and validation of larixyl acetate as a potent TRPC6 inhibitor. Mol Pharmacol 89(1):197-213

43. Stadtmann A, Brinkhaus L, Mueller H, Rossaint J, Bolomini-Vittori M, Bergmeier W, Van Aken H, Wagner DD, Laudanna C, Ley K, Zarbock A (2011) Rap1a activation by CalDAG-GEFI and p38 MAPK is involved in E-selectin-dependent slow leukocyte rolling. Eur J Immunol 41(7):2074-2085

44. Mayadas TN, Cullere X (2005) Neutrophil $\beta 2$ integrins: moderators of life or death decisions. Trends Immunol 26(7):388-395

45. Sel S, Rost BR, Yildirim AO, Sel B, Kalwa H, Fehrenbach H, Renz H, Gudermann T, Dietrich A (2008) Loss of classical transient receptor potential 6 channel reduces allergic airway response. Clin Exp Allergy 38(9):1548-1558

46. Zhu X, Learoyd J, Butt S, Zhu L, Usatyuk PV, Natarajan V, Munoz NM, Leff AR (2007) Regulation of eosinophil adhesion by lysophosphatidylcholine via a non-store-operated $\mathrm{Ca}^{2+}$ channel. Am J Respir Cell Mol Biol 36(5):585-593

47. Kim EY, Yazdizadeh Shotorbani P, Dryer SE (2018) TRPC6 inactivation confers protection in a model of severe nephrosis in rats. $\mathrm{J}$ Mol Med (Berl) 96(7):631-644
48. Futosi K, Fodor S, Mocsai A (2013) Neutrophil cell surface receptors and their intracellular signal transduction pathways. Int Immunopharmacol 17(3):638-650

49. Iwig JS, Vercoulen Y, Das R, Barros T, Limnander A, Che Y, Pelton JG, Wemmer DE, Roose JP, Kuriyan J (2013) Structural analysis of autoinhibition in the Ras-specific exchange factor RasGRP1. Elife 2:e00813

50. Bromberger T, Klapproth S, Rohwedder I, Zhu L, Mittmann L, Reichel CA, Sperandio M, Qin J, Moser M (2018) Direct Rap1/ Talin1 interaction regulates platelet and neutrophil integrin activity in mice. Blood 132(26):2754-2762

51. Wynne JP, Wu J, Su W, Mor A, Patsoukis N, Boussiotis VA, Hubbard SR, Philips MR (2012) Rap1-interacting adapter molecule (RIAM) associates with the plasma membrane via a proximity detector. J Cell Biol 199(2):317-330

52. Robledo-Avila FH, Ruiz-Rosado JD, Brockman KL, Kopp BT, Amer AO, McCoy K, Bakaletz LO, Partida-Sanchez S (2018) Dysregulated calcium homeostasis in cystic fibrosis neutrophils leads to deficient antimicrobial responses. J Immunol 201(7): 2016-2027

53. Steinckwich N, Myers P, Janardhan KS, Flagler ND, King D, Petranka JG, Putney JW (2015) Role of the store-operated calcium entry protein, STIM1, in neutrophil chemotaxis and infiltration into a murine model of psoriasis-inflamed skin. FASEB J 29(7):30033013

54. Latasiewicz J, Artz A, Jing D, Blanco MP, Currie SM, Avila MV, Schnoor M, Vestweber D (2017) HS1 deficiency impairs neutrophil recruitment in vivo and activation of the small GTPases Rac1 and Rap1. J Leukoc Biol 101(5):1133-1142

55. Li Q, Huth S, Adam D, Selhuber-Unkel C (2016) Reinforcement of integrin-mediated T-lymphocyte adhesion by TNF-induced insideout signaling. Sci Rep 6:30452

56. Stadtmann A, Zarbock A (2012) CXCR2: from bench to bedside. Front Immunol 3:263

57. Nywening TM, Belt BA, Cullinan DR, Panni RZ, Han BJ, Sanford DE, Jacobs RC, Ye J, Patel AA, Gillanders WE, Fields RC, DeNardo DG, Hawkins WG, Goedegebuure P, Linehan DC (2018) Targeting both tumour-associated CXCR2 ${ }^{+}$neutrophils and $\mathrm{CCR} 2^{+}$macrophages disrupts myeloid recruitment and improves chemotherapeutic responses in pancreatic ductal adenocarcinoma. Gut 67(6):1112-1123

Publisher's note Springer Nature remains neutral with regard to jurisdictional claims in published maps and institutional affiliations. 